\title{
Minimum Performance Standards for Showerheads in Australia- the Benefits and the Barriers
}

\author{
Denise Day and Stuart White \\ Institute for Sustainable Futures
}

\section{ABSTRACT}

This paper discusses the potential merits and opportunities of introducing national minimum performance standards (MPS) for water efficient appliances, in particular showerheads. At a national level the introduction of MPS for showerheads by 2005 is expected to result in a reduction in the demand for water by over 79 GL/annum by 2015 . The reduction in energy consumption associated with reduced water heating needs by water efficient showerheads is 7.7 million GJ/annum, while greenhouse gas emissions will be reduced by 1.3 million tones $\mathrm{CO}_{2}$ /annum, by 2015 .

This initiative will generate benefits to an array of stakeholders. These benefits include: increased allocation of water for environmental flows, reduced demand on groundwater sources, reduced wastewater flows and associated pollution, and financial benefits to water utilities, particularly if the utility is experiencing water supply or wastewater treatment constraints. Regulation will also protect the investment (estimated to be in the order of $\$ 16$ million) that a number of water utilities are making in incentive and retrofit programs.

The most effective form of regulation to achieve the greatest outcomes in terms of reducing water and energy consumption and greenhouse gas emissions is regulation that controls the supply of showerheads on the basis of flow rate. The MPS being proposed is $9 \mathrm{~L} / \mathrm{minute}$, and regulation would involve mandatory labelling of showerheads and compliance with the AAA-rating. The legislative options and challenge of introducing such a requirement within the current regulatory environment are discussed.

\section{KEY WORDS}

Showerheads, minimum performance standards, regulation

\section{INTRODUCTION}

Showers account for approximately $30 \%$ of total residential indoor water consumption, or about $60 \mathrm{~kL} / \mathrm{household} / \mathrm{annum}$.

Regulation of water using appliances was introduced in the United States in 1992 through the U.S. Energy Policy and Conservation Act. This initiative has been extremely effective, with an estimated reduction in demand for water of $48.4 \mathrm{~L} /$ person/day by 2020 . Average utility savings across the United States are in the order of $\$$ US7,500 million (\$US26 per person), while the savings to communities total $\$ U S 35,000$ million ( $\$ 127$ per person) (Dickson et al 2001). The precedent for regulating water efficient products in Australia was set with the introduction of a policy covering 6/3-litre dual flush toilets. The water 
conservation effects of this technology has been significant, with the average flush volume decreasing from 11 litres in 1982 to 3.8 litres in 1993.

In Australia the regulatory framework differs substantially between States and Territories, although, in general the Plumbing Code or MP 52 is called up in plumbing or building regulations. Standards Australia is responsible for maintaining and distributing the following publications associated with plumbing work and products.

Table 1 Plumbing standards and related publications.

\begin{tabular}{|l|l|}
\hline \multicolumn{1}{|c|}{ Standard/ publication } & \multicolumn{1}{c|}{ Description } \\
\hline $\begin{array}{l}\text { AS/NZS 3500 National Plumbing and Drainage } \\
\text { Code }\end{array}$ & $\begin{array}{l}\text { Covers water supply from the reticulation main into the } \\
\text { premises. With respect to plumbing appliances the } \\
\text { requirements are detailed in MP 52. }\end{array}$ \\
\hline $\begin{array}{l}\text { MP52 2001 Manual of Authorization Procedures } \\
\text { for Plumbing and Drainage Products }\end{array}$ & $\begin{array}{l}\text { Defines the operation of the National Certification of } \\
\text { Plumbing and Drainage Products (NCPDP) Scheme. }\end{array}$ \\
\hline $\begin{array}{l}\text { SAA MP78- 1999 Manual for the assessment of } \\
\text { risks of plumbing products }\end{array}$ & $\begin{array}{l}\text { Reference document for risk identification, analysis, } \\
\text { assessment and treatment of plumbing and drainage } \\
\text { products, appliances and equipment within the scope } \\
\text { of the NCPDP Scheme. }\end{array}$ \\
\hline $\begin{array}{l}\text { MP64- Manual of assessment procedures for } \\
\text { water efficient appliances }\end{array}$ & $\begin{array}{l}\text { The specified water ratings for a range of water using } \\
\text { appliances. }\end{array}$ \\
\hline $\begin{array}{l}\text { AS/NZS 3662- Water supply- Water efficient } \\
\text { mains pressure shower spray heads }\end{array}$ & $\begin{array}{l}\text { Outlines the performance specifications for water } \\
\text { efficient showerheads. Currently being reviewed and } \\
\text { updated. }\end{array}$ \\
\hline
\end{tabular}

\section{BENEFITS OF SHOWERHEAD REGULATION}

The following calculations are for the residential sector only, and are based on a showerhead flow rate of $9 \mathrm{~L} / \mathrm{min}$ (AAA-rated).

\section{Benefits to the householder}

Replacing a standard showerhead, which discharges up to $25 \mathrm{~L} / \mathrm{min}$, with a AAA-rated showerhead saves the average household approximately $20 \mathrm{~kL} / \mathrm{a}$ (Sarac et al 2000; Day et al 2000). The associated energy savings from reduced hot water use amount to between 500-800 kWh per year (when an electric water heater is used). The evaluation of the SEDA Smart Showerhead Program estimated benefits to the customer (Sydney region) from water and energy savings at $\$ 660$ over the 15 years lifetime of a showerhead (Day and White 2000).

\section{Benefits to the environment}

1. Water: At a national level the introduction of MPS standards for showerheads in (say) 2005 would be expected to result in a reduction in demand for water of over $79 \mathrm{GL} / \mathrm{a}$ by 2015. Figure 1 shows the projected annual water use by showerheads (reference case), and the predicted water use, assuming regulation in 2005 MPS for showerheads.

Reducing water demand can result in increased stream flows or reduced demand on groundwater sources. The allocation of water for environmental requirements is of growing concern and is likely to place additional constraints, and costs, on new water supplies in the future (White 1998). In addition, reduced demand for water also reduces wastewater flows and the associated environmental impacts from pollution (Maddaus 1987). 


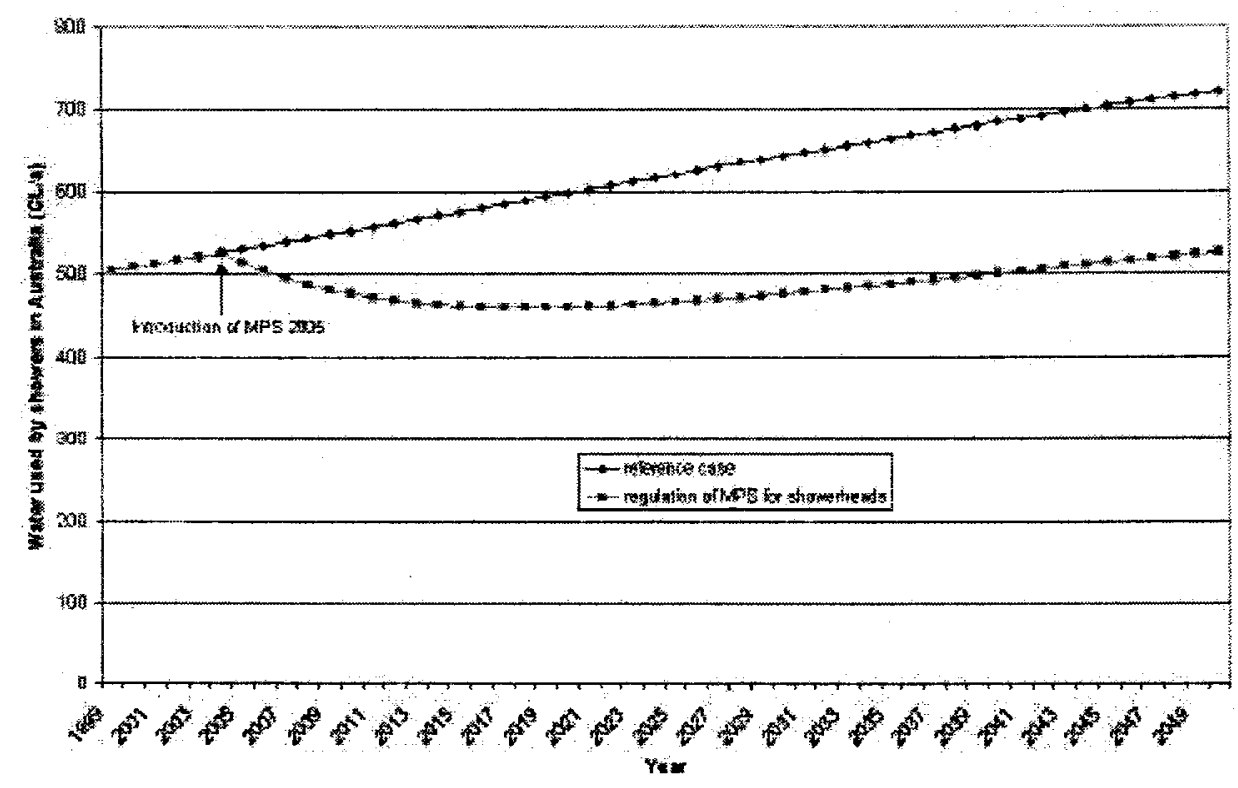

Figure 1 Impact of regulation on water usage by showers.

2. Energy. In terms of energy savings from reduced water heating needs, the expected reductions in water use would result in a saving of 7.7 million GJ/a by 2015 . This does not include the reduced energy requirements for pumping and treating both potable water and wastewater.

3. Greenhouse gas emissions: The reduction in greenhouse gas emissions associated with reduced energy consumption is approximately 1.3 million tonnes/a by 2015 . Again, these values do not include the greenhouse gas reductions associated with the reduced energy requirements for supplying and treating water and wastewater.

\section{Benefits to utilities}

A reduction in the demand for water provides several financial benefits to water utilities, particularly if the utility is experiencing water supply or wastewater treatment constraints. Financial benefits include: avoiding or deferring the need for new capital works, reduced operating costs associated with pumping and water treatment, reduced wastewater loads and costs associated with pumping of effluent and chemicals for treatment (White 1998).

There are also opportunity costs associated with not implementing national regulation on water efficient showerheads. Regulation will protect the investment that a number of utilities (e.g. Sydney Water, Rous County Council, Environment ACT, Kalgoorlie-Boulder and Maroochy Shire Council) are making in incentive and retrofitting programs. Such programs will be undermined if water inefficient showerheads are installed as replacements in the future. Regulation will negate the need for water utilities to carry out retrofit programs and will protect existing investments. A conservative estimate of the total cost of these programs to date is $\$ 16$ million.

\section{BARRIERS TO SHOWERHEAD REGULATION}

This section discusses some of the potential barriers to introducing MPS for showerheads. In general, the barriers relate to negative impacts on stakeholder groups and are issues that are likely to arise during stakeholder consultations. Where possible, solutions to overcome or mitigate the barriers have been identified, however, many of the issues will need to be discussed in greater detail with the relevant stakeholders. 


\section{Legal}

1. Mutual Recognition Act: this Act enables goods that can be sold in one State or Territory to be sold freely in any other state or territory, even where the goods do not comply with regulatory standards in the place where they are sold. The products must be installed in accordance with the plumbing and drainage regulations of the local regulator.

The implication of this Act is that all States and Territories would need to be in agreement and willing to implement regulations that exclude the sale of non-efficient showerheads.

2. Competition Principles Agreement: the basis of this agreement is the National Competition Policy (NCP). The guiding principle of the NCP is that legislation should not restrict competition unless it can he demonstrated that the:

- benefits of the restriction to the community as a whole outweigh the costs; and

- objectives of the legislation can only be achieved by restricting competition.

Proposals for new legislation that restrict competition need to be accompanied by evidence that the legislation is consistent with the above principle. When Governments are implementing laws that restrict competition the NCP requires them to consider a number of factors to determine what is in the public interest (Public Interest Test). Factors relevant to the regulation of MPS for showerheads include:

- Laws and policies relating to ecologically sustainable development (ESD).

- Social welfare and equity, including community service obligations.

- The efficient allocation of resources.

Provisional investigations indicate that the broad-raning benefits of regulating for MPS for showerheads far outweigh the costs. In relation to the public interest test the regulation of MPS for showerheads will generate significant benefits in terms of ESD, resource efficiency, financial benefits to customers.

A requirement to supply AAA-rated showerheads will stimulate product innovation and design by the Australian showerhead manufacturers. The restriction on competition in the showerhead market as a result of regulation is likely to be offset by improved global competitiveness and the potential for import substitution. One particular market opportunity is the United States, where the existing regulations specify a flow rate of $9.5 \mathrm{~L} / \mathrm{min}$. There are also extensive opportunities for further development and production of luxury and speciality showerhead lines within Australia. As most of these lines are currently imported this would enhance import substitution, particularly from Europe.

A true understanding of the implications of regulation on competition will require a thorough investigation of the tapware market in Australia, including consultations with manufacturers and importers and a comprehensive cost-benefit analysis. These issues will need to be addressed in detail as part of a Regulatory Impact Statement (RIS).

\section{Consumer barriers}

1. Public outcry: due to poor performance of some early models of water efficient showerheads public perception of their effectiveness and ability to provide a comfortable shower is generally poor. 
To an extent, the performance of water efficient showerheads is dictated by the standard. This has undergone several reviews, and is currently in the process of being upgraded. These improved performance specifications have raised the profile of water efficient showerheads, which is supported by numerous consumer report and surveys. Results from a Choice magazine user trial (Choice 1998) found that the majority of AAA-rated showerheads tested "provided a reasonable comfortable, effective shower."

Community acceptance is evident by the uptake rate for retrofit programs, such as Sydney Water's Residential Retrofit Program. To date over 140,000 AAA-rated showerheads have been installed in the Sydney region, with a high level of customer satisfaction (less than $1 \%$ of complaints concerned showerheads) (SWC 1999a).

In a survey conducted by SWC $94 \%$, of participants were aware of the existence of water saving showerheads, while only one in ten were definitely not interested in installing them. In terms of performance, $48 \%$ of survey participants stated that the water saving showerhead was just as good as their old model, $33 \%$ stated that it was better, $17 \%$ worse (SWC 1999b). A survey of participants in the SEDA Smart Showerhead Program identified that $77 \%$ rated the quality of the shower provided by the AAA-rated showerhead as either very good or good, $17 \%$ acceptable, and only $7 \%$ as poor or very poor (Ellis et al 2000 ).

Community response to regulating for MPS for showerheads has also been extremely positive. A customer research found that $87 \%$ of participants supported a requirement that new buildings and major renovations be fitted with a water saving showerhead, while $73 \%$ of respondents support national regulation that gradually phased out the availability of showerheads which are not water saving types (SWC 1999b).

2. Showerhead manufacturers and importers: although the majority of tapware manufacturers and importers market water efficient models of showerheads, the range is limited compared to that of non-efficient models (currently there is only one line of matching tapware that incorporates a AAA-rated showerhead). Some consumers have identified that an ability to match showerhead design to existing bathroom fixtures is important (SWC1999b). Supplying this demand would require conversion of the existing product range, which would confer costs to industry for research and development (prototyping and testing), changing manufacturing processes, product registration (labelling scheme) and possibly marketing. These costs could be mitigated by the provision of fina ncial support from government for research and development.

A detailed investigation of the tapware industry and markets in Australia, and discussions with manufacturers and importers, are necessary to develop and implement a strategy to identify and address barriers, and to develop markets for water efficient showerheads. A comprehensive marketing and dissemination campaign will be required to inform the public, showerhead retailers and the plumbing and building industry of regulatory changes and the implications of the changes.

3. Utilities: water utilities will obtain a significant benefit from the introduction of MPS for showerheads, including reduced operating and capital costs in relation to all parts of the water cycle and associated infrastructure. The actual benefit will vary by location, due to the different costs and stages in relation to augmentation, but in almost no case in Australia would the marginal cost of water be less than the unit cost of water saved through this means (Howe and White 1999). 
One issue that has been raised by water utilities is the cost of foregone revenue and foregone profit as a result of reduced water sales. However, if the impact of regulating for MPS for showerheads were assessed from the perspective of the costs and benefits to the community as a whole (as it should be an economic evaluation using the Total Resource Cost test), foregone revenue should be seen as a transfer payment between customers and the utility (see Table 2), and should not be included in the evaluation of impacts.

Table 2 Components of the Total Resource Cost test.

\begin{tabular}{|l|l|l|l|}
\hline Parameter & Water Service Provider & \multicolumn{1}{c|}{ Customers } & Total Resource Cost test \\
\hline Costs & $\begin{array}{l}\text { program costs (PC) } \\
\text { foregone revenue (FR) }\end{array}$ & customer costs (CC) & -PC-FR-CC \\
\hline Benefits & avoided cost (AC) & reduced bills (RB) & + +AC+RB \\
\hline Net benefit & + AC-PC-FR & +RB-CC & $+A C+$ RB-PC-FR-CC \\
\hline
\end{tabular}

\section{Technical barriers}

There is very little documentation of technical problems associated with water efficient showerheads, either from Australia or internationally. Many of these issues are currently being addressed as part of the upgrade of the showerhead standard AS/NZS 3662.

1. Instantaneous hot water systems (gas and electric): Some problems with temperature and flow fluctuations have been reported as a result of using water efficient showerheads with some models of instantaneous hot water systems. In some instances the flow from the showerhead has been insufficient to maintain the operation of the hot water system. The extent of this problem is unknown and would require further investigation of the technical specifications of instantaneous water heaters on the market and historical data relating to sales of instantaneous hot water systems.

2. . Low water pressure and gravity feed systems: the risk of temperature fluctuations from reduced cold water pressure may be increased with water efficient showerheads, where plumbing lines are inadequate to maintain proper water pressure to showers when other water using appliances are in use (Rocky Mountain Institute 1991). There are some models of showerheads on the market (e.g. Delrana Lopez and Dolpfun Dol 30) that are suited to these circumstances. Other solutions include and anti-scald valve setting water heaters at a lower temperature, or having plumbing redone correctly.

3. Blockage: blockage is an issue with both efficient and non-efficient showerheads, and is due to particulate matter or lime in the water supply. This problem is likely to be more common in rural areas as a result of poor water quality. There are currently self-cleaning models of water efficient showerheads on the market (e.g. Teledyne Water Pik). This problem would be investigated further as part of the upgrade of the showerhead standard.

\section{REGULATORY OPTIONS}

The principal forms of regulation form part of a continuum from self-regulation to explicit government regulation. Each form of regulation has different advantages and disadvantages; all of which were assessed in identifying the form of regulation best suited for addressing this particular issue.

On the basis of achieving the desired outcomes in terms of cost effectiveness, resource use efficiency, administrative simplicity, flexibility, and equity the preferred option is explicit government regulation. Explicit government regulation offers more certainty, including industry-wide coverage, and greater level of scrutiny and effectiveness due to the 
availability of legal sanctions. If a requirement for MPS for showerheads was included in the existing plumbing regulations, budgetary costs would be limited, as the States and Territories have established agencies for administering plumbing regulations (e.g. Plumbing Industry Commission in Victoria) and compliance monitoring arrangements.

\section{LEGISLATIVE OPTIONS AND PROCESSES}

Five legislative options were identified, including local development and building controls, the Building Code of Australia, the energy labelling and Minimum Energy Performance Standards (MEPS), the Trade Practices Act (and related State and Territory Acts) and State and Territory plumbing regulations.

Of these options, the most appropriate is likely to be regulation of showerheads through the plumbing regulations (expanding on the current requirement in MP 52 to install showerheads according to the standard MP64). At present the State and Territory Acts that the plumbing regulations are made under do not provide the power of authority to regulate the supply of goods, only the installation. In order to ensure that only water efficient showerheads are available for sale the powers of authority will need to be amended so that plumbing regulations have the power to restrict the supply of plumbing appliances (possibly on the basis of resource conservation/ efficiency or environmental outcomes). This approach is similar to electricity regulations that have the power of authority to regulate the supply of goods on the basis of safety considerations.

Another variation is to amend a separate schedule to AS 3500 . The plumbing regulations could then specify that appliances listed in (for example) Schedule A cannot be supplied unless they comply with the relevant standard. This approach would also provide the flexibility to modify or update the standard without having to amend the regulations and to regulate for other water efficient appliance at a later date. Alternately the same outcome could be achieved by establishing a model similar to MEPS for water-using equipment.

The best practice processes and requirements for developing and amending legislation and regulation have been established by the Office of Regulation (ORR 1998). The key stages of this process are to initiate stakeholder consultations to ensure that all issues are identified and examined, and the preparation of a Regulatory Impact Statement.

\section{CONCLUSIONS}

Regulating for MPS for showerheads is one of the lowest unit cost means of reducing water and energy consumption and greenhouse gas emissions in Australia. These impacts are long-term and support intergenerational equity, a key principle of ecologically sustainable development (ESD). Regulating the sale of goods on the basis of conservation objectives would be landmark initiative by the Australian government and would generate extensive financial benefits to a wide range of stakeholders.

The next step forward is to initiate discussions with stakeholders (including government agencies) and undertake a more detailed assessment of the impacts.

\section{ACKNOWLEDGEMENTS}

This study was funded by the NSW Sustainable Energy Development Authority and the QLD Environmental Protection Agency. 


\section{REFERENCES}

Choice (1998). Water-efficient shower heads. December 1998.

Day, D. A. and White, S. (2000). Evaluation of the Smart Showerhead Program. Prepared by the Institute for Sustainable Futures for Sydney Water Corporation, August 2000.

Day, D. A., Sarac. K, Carew, A. and White, S. (2000). Evaluation of the Rous Regional Demand Management Strategy. Prepared by the Institute for Sustainable Futures for Rous Water, February 2000.

Dickson, M. A., Maddaus L. A., and Maddaus, W. O. (2001). Benefits of the United States Nationwide Plumbing Efficiency Standards. Canal de Isabel II and International Water Association conference: Efficient Use and Management of Water for Urban Supply, Madrid, 21-23 May 2001.

Ellis, M., White, S., and Sarac, K. (2000). SEDA Smart Showerhead Program: Final Report and Evaluation. Prepared by the Institute for Sustainable Futures for the Sustainable Energy Development Authority, September 2000.

Howe, C. and White, S. (1999). Integrated Resource Planning for Water and Wastewater: Sydney Case Studies, Water International, 24 (4): 356-362.

Maddaus, W. O. (1987). Water Conservation, American Water Works Association.

Office of Regulation Review (1998). A Guide to Regulation. December 1998.

Rocky Mountain Institute (1991). Water Efficiency: A Resource for Utility Managers, Community Planners, and Other Decision-makers.

Sarac, K., Day, D. A, and White, S. (2000). Evaluation of the Shellharbour Residential Retrofit Program. Prepared by the Institute for Sustainable Futures for Sydney Water Corporation.

Sydney Water Corporation (1999a). Evaluation of the trial water saving retrofit program in Shellharbour: Research report, October 1999.

Sydney Water Corporation (1999b). Community views on water saving programsResearch report, July 1999.

White, S. (1998). Introduction. In Wise Water Management: A Demand Management Manual for Water Utilities. Ed. S. White. Water Services Association of Australia Research Report No. 86, November 1998.

\section{CONTACT}

Contact name- Denise Day

Organisation- Institute for Sustainable Futures, University of technology, Sydney

Telephone- (02) 92094375

Facsimile- (02) 92094351

Email-Denise.Day@uts.edu.au 